\title{
FINITE ELEMENT MODELING FOR MAXIMUM TEMPERATURE IN FRICTION STIR WELDING OF AA 1100 AND OPTIMIZATION OF PROCESS PARAMETER BY TAGUCHI METHOD
}

\author{
Renju Mohan ${ }^{1}$, N. R. Rajesh ${ }^{2}$, Satheesh Kumar $S^{3}$ \\ ${ }^{1}$ MTech Student, Department of Mechanical Engineering, GEC Barton Hill, Kerala, India \\ ${ }^{2}$ Asst. Professor, Department of Mechanical Engineering, GEC Barton Hill, Kerala, India \\ ${ }^{3}$ Asst. Professor, Department of Mechanical Engineering, GEC Barton Hill, Kerala, India
}

\begin{abstract}
In the present work a three dimensional finite element thermal analysis of friction stir welding has been carried out in Comsol Multiphysics software. In the present model only heat generation due to friction is considered. The thermal profile obtained from the simulation has shown good agreement with the previously published experimental results. Three factors viz. axial force, welding speed and rpm each having three different levels was studied. The optimization of the process parameters for maximum temperature has been carried out by Taguchi method based on Taguchi's L9 orthogonal array. In this approach, each response ie. Temperature is transferred to corresponding signal to noise ratio by using Taguchi's larger the better criterion (LBT). The optimum welding parameters obtained after the analysis are $F=5000 \mathrm{~N}, S=80 \mathrm{~mm} / \mathrm{min}$ and $\mathrm{N}=1600 \mathrm{rpm}$. A conformation test is conducted by using these process parameters. The maximum temperature obtained was $590.62^{\circ} \mathrm{C}$ which is $89.4 \%$ of melting temperature of the material.
\end{abstract}

Keywords: Finite element analysis, Comsol Multiphysics, Friction stir welding, Taguchi etc...

\section{INTRODUCTION}

Solid state welding is a group of welding process which is operated below the melting point of base metal being joined without the addition of filler metal. Pressure may or may not be applied depending up on the requirement. In all solid state welding process pressure and temperature individually or in combination produces coalescence of the base metal without producing significant melting.

Friction stir welding is a solid state welding process invented by The Welding Institute (TWI) of UK in 1991. The work pieces that are to be joined are clamped together on a backing plate. A rotating non consumable tool with a profiled pin and large concentric shoulder slowly plunged in to the joint line between two plates which are clamped together. Here coalescence is created by the combined action of frictional heating between tool and work pieces and the plastic deformation of base metal due to the rotation of the tool. $95 \%$ of heat generated in the process is transferred to the work piece and only 5\% flows in to the tool ${ }^{[1]}$. The friction heat generated softens the material around the pin and moves it from the front of the pin to the back due to the rotation and translation of the tool.

In conventional welding, dissimilar metals are very difficult to join because of different physical and chemical properties of base metals. The heat generated in the fusion welding process and the subsequent microstructure changes are the main reason for the decay of mechanical properties like strength, hardness and ductility of welded components. Similarly fusion welding of aluminium leads to poor solidification, microstructure and porosity in the fusion zone. Friction stir welding overcomes majority of the limitations of conventional fusion welding processes and in addition extensive thermo mechanical deformations induces dynamic recrystallization and recovery that refines the stir region. Therefore friction stir welded joints have improved mechanical properties such as tensile strength, ductility, hardness than conventional fusion welded joints ${ }^{[2]}$.

Taguchi methods developed by Genichi Taguchi to improve the quality of manufacturing goods are recently applied to the field of engineering, biotechnology, marketing and advertising. The Taguchi method is a very powerful tool for carrying out experimental design. The main aim of the Taguchi methods is to produce an optimum result by analyzing the statistical data which have been given as an input function. This method allows limited number of experimental runs by utilizing a well balanced experimental design called orthogonal array design and signal to noise $(\mathrm{S} / \mathrm{N})$ ratio. Taguchi methods have been successfully utilized by Lakshminarayanan et.al. ${ }^{[3]}$ for optimizing the process parameters of friction stir welding of RDE-40 aluminium alloy. The result shows that the rotational speed, welding speed and axial forces are the main parameters which affect the tensile strength of the joint. Vinod kumar et.al. $^{[4]}$ uses taguchi method to optimize process parameters namely cutting speed, feed, point angle and chisel edge width in drilling of glass fiber reinforced polymer (GFRP) composites. Many researchers use taguchi methods for planning, designing and optimization of many engineering problems. Therefore the aim of this study is to 
optimize the process parameters of friction stir welding for optimum welding temperature by Taguchi methods.

\subsection{Finite Element Modeling of FSW}

Various FEM studies are conducted by many researchers to investigate the heat generation, residual stress and microstructure developments. Maximum temperature developed in FSW of 304L stainless steel was studied by Prasanna et.al. ${ }^{[5]}$ by using ANSYS. The result of simulation shows good agreement with the experimental result and peak temperature developed was $1056.835^{\circ} \mathrm{C}$. Biswas et.al. ${ }^{[6]}$ studied the effect of tool geometries on the thermal history of aluminium alloy 1100. They found that tool geometry with concave shoulder and conical pin was found to be preferable for FSW of AA 1100. Zhu et.al. ${ }^{[7]}$ studied the thermal and residual stress in friction stir welding of 304L stainless steel by the finite element code WELDSIM. The effect of fixture release after the welding on the residual stress is also computed. Abdul Arif et.al. ${ }^{[8]}$ studied the thermo mechanical modeling of residual stresses of friction stir welding of dissimilar alloys. In the present study a three dimensional thermal analysis is conducted in Comsol Multiphysics software to evaluate the maximum temperature developed in the friction stir welding of AA1100. The heat generated in FSW plays significant role in the development of microstructure and the resultant mechanical properties. The effect of welding parameters on the maximum temperature development has been studied and optimized by taguchi method.

\section{HEAT GENERATION MODEL}

Accurate modeling of heat generation in friction stir welding is essential to evaluate the maximum temperature. Since the thermal history of the work piece directly affect the mechanical properties, residual stress and microstructure.

The total heat generated over the interface between shoulder and work piece is $Q_{l}$ which is calculated by the following expression $^{[6]}$.

$$
Q_{1}=\frac{2}{3} \pi \mu p \omega\left(R_{s}^{3}-R_{p}^{3}\right)
$$

Where $\mu$ is the coefficient of friction, $\mathrm{p}$ is the axial pressure exerted by the tool on the plate. This can be calculated by dividing the normal force to the area of shoulder. $\omega$ is the angular velocity of the tool. $R_{s}$ and $R_{p}$ are the radius of shoulder and pin respectively. The heat generated from the tool pin side surface is $Q_{2}$ which is calculated as follows ${ }^{[6]}$.

$$
Q_{2}=\omega R_{p} F_{v}
$$

Where $F_{v}$ is the frictional force experienced by the tool pin vertical surface.

$$
F_{v}=\mu F
$$

Here $F$ is the reaction force generated when tool moves forward along the joint.

$$
F=\left(h_{p} \times d_{p}\right)\left(\sigma_{y}\right)
$$

Where $\mu, \sigma_{y}$ are the coefficient of friction and yield stress of the material at $80 \%$ of the melting point of the material ${ }^{[5]} h_{p}$ is the height of the tool pin and $d_{p}$ is the diameter of the tool pin. Therefore the total heat generated

$$
\begin{aligned}
Q_{\text {total }} & =Q_{1}+Q_{2} \\
Q_{\text {total }} & =\frac{2}{3} \pi \mu p \omega\left(R_{s}^{3}-R_{p}^{3}\right)+\omega R_{p} F_{v}
\end{aligned}
$$

The heat flux distribution over the shoulder surface is given as ${ }^{[5]}$.

$$
q_{\text {shoulder }(r)}=\frac{3 Q_{r} r}{2 \pi R_{S}^{3}} \quad \text { for } \mathrm{r} \leq r_{0}
$$

Here $r_{0}$ is the shoulder outer radius. However it is very difficult to formulate the radius dependent heat flux distribution. Therefore for simplicity a uniform heat distribution across the shoulder surface is considered. For that an average value of shoulder radius and pin radius was taken ${ }^{[5]}$ as shown in equation (7).

$$
r=\frac{R_{S}+R_{p}}{2}
$$

The heat flux distribution over the vertical surface of the pin and work piece is given as

$$
q_{p}=\frac{Q_{2}}{(A)_{p s}}
$$

Where $(A)_{p s}$ is the area of pin's vertical surface. The application of boundary conditions and heat flux can be shown in fig. 1.

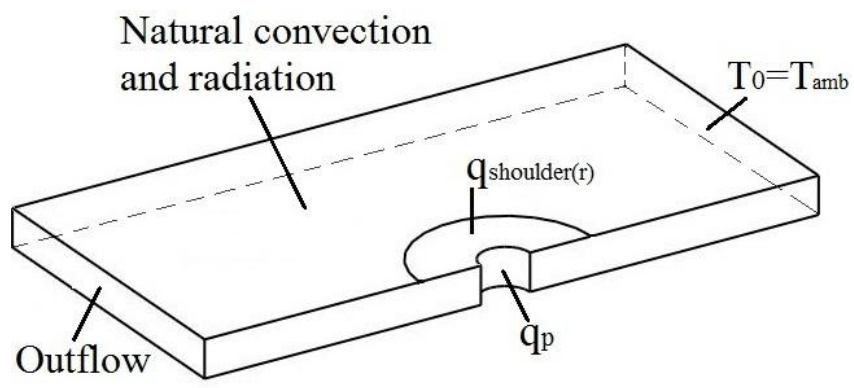

Fig.1. Boundary conditions and Heat flux

\section{3D FINITE ELEMENT MODEL}

The fundamental law governing all heat transfer is the first law of thermodynamics, commonly referred to as the principle of conservation of energy. However, internal energy, $U$, is a rather inconvenient quantity to measure and use in simulations. Therefore, the basic law is usually rewritten in terms of temperature $T$. Comsol Multiphysics $4.3 \mathrm{~b}$ is used to solve the governing differential equation. 
$\nabla \cdot(k . \nabla T)+Q=\rho C_{p} u . \nabla T$

Where $\rho$ is the density, $C_{\mathrm{p}}$ is the specific heat capacity at constant pressure, $k$ is the thermal conductivity, $\mathrm{u}$ is the velocity vector, T is absolute temperature, $Q$ contains heat sources other than viscous heating.

The weld coupons selected for the analysis are $6 \mathrm{~mm}$ thick AA1100 aluminium alloy having $300 \mathrm{~mm}$ length and 100 $\mathrm{mm}$ width. Since the material properties changes with temperature, temperature dependent properties of aluminium alloy [6] given in table 1 is used for this analysis. Temperature dependent friction of steel aluminium combination is also used.

Table1 - Temperature Dependent properties of AA 1100

\begin{tabular}{|c|c|c|}
\hline $\begin{array}{l}\text { Temperature } \\
{ }^{\circ} \mathrm{C}\end{array}$ & $\begin{array}{l}\text { Thermal } \\
\text { Conductivity } \\
\mathrm{W} / \mathrm{m}^{\circ} \mathrm{C}\end{array}$ & $\begin{array}{l}\text { Heat Capacity } \\
\mathrm{J} / \mathrm{Kg}^{\circ} \mathrm{C}\end{array}$ \\
\hline 37.8 & 162 & 945 \\
\hline 93.3 & 177 & 978 \\
\hline 148.9 & 184 & 1004 \\
\hline 204.4 & 192 & 1028 \\
\hline 260 & 201 & 1052 \\
\hline 315.6 & 207 & 1078 \\
\hline 371.1 & 217 & 1104 \\
\hline 426.7 & 223 & 1133 \\
\hline
\end{tabular}

Table 2 - Temperature Dependent friction coefficient of aluminium and steel combination

\begin{tabular}{|c|c|}
\hline Temperature $^{\circ} \mathrm{C}$ & Friction Coefficient $\mu$ \\
\hline 22 & 0.11 \\
\hline 160 & 0.11 \\
\hline 200 & 0.26 \\
\hline 400 & 0.35 \\
\hline 580 & 0.47 \\
\hline
\end{tabular}

A constant convection coefficient of $30 \mathrm{~W} / \mathrm{m}^{2}{ }^{\circ} \mathrm{C}$ was used. ${ }^{[7]}$ Heat transfer due to radiation is taken in to consideration by adding a boundary condition called 'surface to ambient radiation'. A suitable value of 0.4 is assumed as surface emissivity. The ambient temperature is assumed to be $30^{\circ} \mathrm{C}$. Melting temperature of AA1100 is taken as $660^{\circ} \mathrm{C}$. The model has 1188 prism elements, 4508 hexahedral elements, 5210 quadrilateral elements and 1188 triangular elements. The 'translational motion' ability of Comsol Multiphysics is used for simulating the translation behavior of the tool. The Translational Motion node provides movement by translation to model heat transfer in solids. It adds the welding velocity ' $v$ ', contribution to the right-hand side of Equation (9).

Peak temperature distribution along the plate breadth perpendicular to the weld line is plotted and compared with the result of Biswas et.al. ${ }^{[6]}$ as shown in fig.2. Overall, the best fitted results are obtained and are reasonably good.

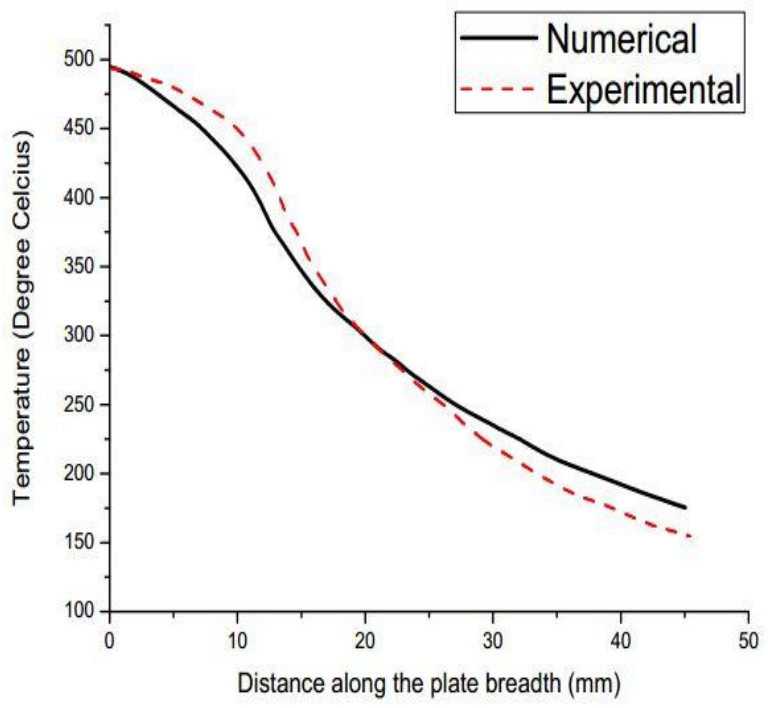

Fig.2. Comparison of numerical and experimental results

\section{TAGUCHI EXPERIMENTAL DESIGN AND OPTIMIZATION}

\subsection{Selection of FSW Parameter and Levels}

As explained earlier the temperature developed during FSW directly affects the mechanical properties, residual stress and microstructure. Therefore optimum welding temperature must be developed. Normally the temperature requirement for FSW is $70-90 \%$ of melting temperature of base metal. In this analysis temperature is optimized by suitably controlling the following parameters.

1. Rotation speed (rpm)

2. Welding speed $(\mathrm{mm} / \mathrm{min})$

3. Axial force $(\mathrm{N})$

The levels of the above mentioned parameters are shown in table 3 .

Table-3 Process parameters and their values

\begin{tabular}{|c|c|c|c|}
\hline \multirow{2}{*}{ Parameter } & \multicolumn{3}{l}{ Level } \\
\cline { 2 - 4 } & 1 & 2 & 3 \\
\hline $\mathrm{F}(\mathrm{N})$ & 4000 & 4500 & 5000 \\
\hline $\mathrm{N}(\mathrm{rpm})$ & 1200 & 1400 & 1600 \\
\hline $\mathrm{S}(\mathrm{mm} / \mathrm{min})$ & 80 & 100 & 120 \\
\hline
\end{tabular}




\subsection{Selection of Orthogonal Array}

Based on the number of factors and levels a suitable Taguchi orthogonal array for the experiment is selected by using MINITAB statistical software. Since there are three factors having three levels each, L9 OA is chosen as shown in table 4.

Table 4 - L9 Orthogonal Array

\begin{tabular}{|c|c|c|c|}
\hline \multirow{2}{*}{ Exp. Run } & \multicolumn{3}{|l|}{ Level } \\
\hline & $\mathrm{F}$ & $\mathrm{N}$ & $S$ \\
\hline 1 & 1 & 1 & 1 \\
\hline 2 & 1 & 2 & 2 \\
\hline 3 & 1 & 3 & 3 \\
\hline 4 & 2 & 1 & 2 \\
\hline 5 & 2 & 2 & 3 \\
\hline 6 & 2 & 3 & 1 \\
\hline 7 & 3 & 1 & 3 \\
\hline 8 & 3 & 2 & 1 \\
\hline 9 & 3 & 3 & 2 \\
\hline
\end{tabular}

\subsection{Experiment Procedure}

FEM analysis is performed according to the selected design of experiment table. The maximum temperature developed in each set of combination is noted and tabulated in table 5 . For each experiment in the orthogonal array, signal to noise $(\mathrm{S} / \mathrm{N})$ ratio is calculated. The quality response is mainly divided in to three main types; the larger-the better (LTB), the smaller-the better (STB) and the nominal-the best (NTB).

$$
S N_{S}= \begin{cases}-10 \log _{10}\left(\frac{1}{k} \sum_{r=1}^{k}\left(y_{i r}^{2}\right)\right) & \text { for STB } \\ 10 \log _{10}\left(\frac{S_{i}^{2}}{\bar{y}_{i}^{2}}\right) & \text { for NTB } \\ -10 \log _{10}\left(\frac{1}{k} \sum_{r=1}^{k}\left(\frac{1}{y_{i r}^{2}}\right)\right) & \text { for LTB }\end{cases}
$$

Where $\mathrm{y}_{\mathrm{i}}$ is the calculated average and $\mathrm{Si}$ is the standard deviation. $y_{\text {ir }}$ indicates at the $\mathrm{i}^{\text {th }}$ experiment or measured characteristic value. $\mathrm{k}$ denotes the number of measurements. The $\mathrm{S} / \mathrm{N}$ ratio is calculated based on LTB criterion and tabulated in the table 5 .

\section{RESULTS AND DISCUSSION}

In the present study the effect of process parameters on the temperature development were examined. The FEM results of temperature were transferred to $\mathrm{S} / \mathrm{N}$ ratio. The $9 \mathrm{~S} / \mathrm{N}$ ratios were tabulated in the table 5. Statistical software MINITAB is used for calculating mean and $\mathrm{S} / \mathrm{N}$ ratio by using the LBT criterion. Then the graph is plotted as shown in the fig $4 \& 5$. According to Taguchi's idea, maximizing signal to noise ratio will get maximum robustness. The main effects of all control variables are obtained from the graph. From the graph it is understood that temperature will be maximum when $\mathrm{F}=5000 \mathrm{~N}, \mathrm{~N}=1600 \mathrm{rpm}$ and $\mathrm{S}=80 \mathrm{~mm} / \mathrm{min}$. However, that a key weakness of Taguchi method is its assumption of a "main factor only" (or additive model). That is Taguchi ignores interactions. Therefore rather than use inner-outer arrays we can use more efficient and exact methods that are no more difficult to learn and apply to carry Taguchi robust design philosophy in to practice. We can use any of the various experimental and optimization technique available in the literature such as regression/RSM to develop robust design.

\subsection{Conformation Test}

After conducting Taguchi analysis the optimum conditions are obtained. Now by using these optimum process parameters the result should be verified. Numerical analysis are carried out by using $\mathrm{F}=5000 \mathrm{~N}, \mathrm{~N}=1600 \mathrm{rpm}$ and $\mathrm{S}=80 \mathrm{~mm} / \mathrm{min}$. The temperature distribution during the conformation test can be shown in fig. 3. The maximum temperature obtained was $590.62^{\circ} \mathrm{C}$ which is $89.4 \%$ of melting temperature of the material.

\section{CONCLUSIONS}

The results obtained through the numerical analysis of thermal history of AA1100 using Comsol Multiphysics compared fairly well with the experimentally measured thermal profiles. The variation at the different locations was within $5 \%$. Based on the number of influencing factors and their levels an L9 orthogonal array has been chosen and numerical simulations are carried out, then maximum temperature is tabulated. By using statistical tool Minitab temperature datas are transformed to corresponding signal to noise ratio and main effect plot for $\mathrm{S} / \mathrm{N}$ ratio and means are plotted. From the plot optimum parameters can be chosen and a conformation test is carried out. The resulting temperature is within the limit of theoretical working temperature of friction stir welding. 
Table-5 Temperature at the tool workpiece interface under different process parameters and corresponding $\mathrm{S} / \mathrm{N}$ ratio.

\begin{tabular}{|c|c|c|c|c|c|}
\hline \multirow{2}{*}{ Exp Run } & \multicolumn{2}{l|}{ Levels } & \multirow{2}{*}{ Temp } & \multirow{2}{*}{ S/N Ratio } \\
\cline { 2 - 4 } & F & N & S & 396.66 & 51.9684 \\
\hline 1 & 4000 & 1200 & 80 & 428.93 & 52.6477 \\
\hline 2 & 4000 & 1400 & 100 & 458.18 & 53.2207 \\
\hline 3 & 4000 & 1600 & 120 & 409.5 & 52.2451 \\
\hline 4 & 4500 & 1200 & 100 & 444.59 & 52.9592 \\
\hline 5 & 4500 & 1400 & 120 & 546.98 & 54.7594 \\
\hline 6 & 4500 & 1600 & 80 & 421.21 & 52.4900 \\
\hline 7 & 5000 & 1200 & 120 & 526.67 & 54.4308 \\
\hline 8 & 5000 & 1400 & 80 & 561.79 & 54.9915 \\
\hline 9 & 5000 & 1600 & 100 & & \\
\hline
\end{tabular}

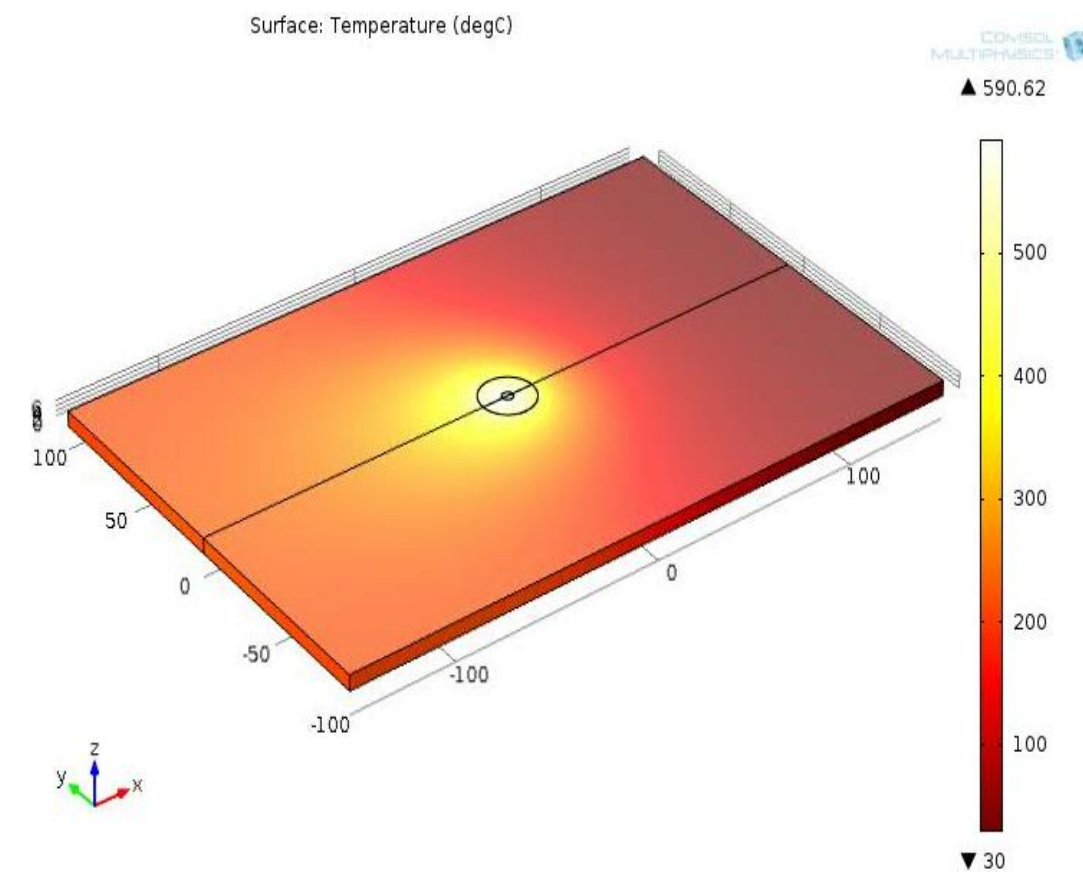

Fig 3 Temperature distribution on the workpiece

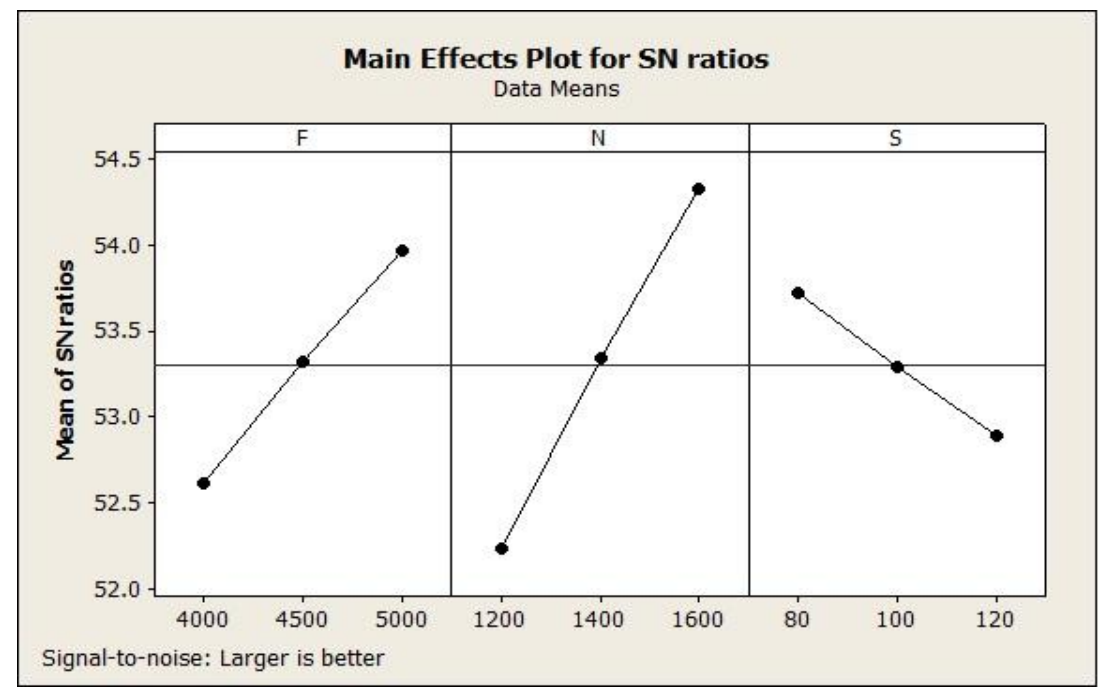

Fig 4 Main effect plot for $\mathrm{S} / \mathrm{N}$ ratio 


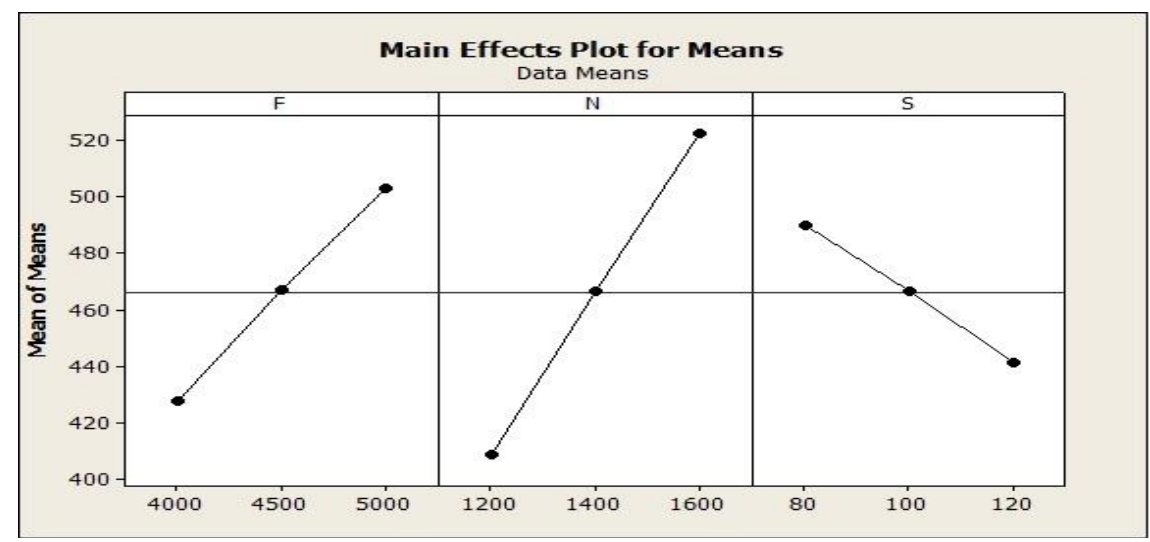

Fig 5 Main effect plot for mean

\section{REFERENCES}

[1]. Chao. Y.J., Qi. X, and Tang, W.2003. Heat transfer in friction stir welding -Experimental and numerical studies, Transaction of the ASME, pp.125.138-145

[2]. Lee WB, Yeon YM, Jung SB. The improvement of mechanical properties of frction stir welded A356 Al alloy. Master Sci Eng 2003; A355:154-9.

[3]. A. K. Lakshminarayanan, V. Balasubrahmanyan. Process parameters optimization for friction stir welding of RDE-40 aluminium alloy using Taguchi technique; Trans.Nonferrous Met.Soc China 2008.18. 548-554

[4]. Vinod kumar vankanti, Venkateswarlu ganta; Optimization of process parameters in drilling of GFRP composite using Taguchi method; Journal of material research and technology.2014;3(1);35-41.

[5]. P.Prasanna, B. Subba Rao, G. Krishna Mohana Rao; Finite element modeling for maximum temperature in friction stir welding and its validation; Int J Adv Manuf Technol; 2010;51:925-933.

[6]. P.Biswas, N.R Mandal, Effect of tool geometries on thermal history of FSW of AA1100; Supplement to the welding journal, July 2011.

[7]. X.K.Zhu, Y.J.Chao; Numerical simulation of transient temperature and residual stresses in friction stir welding of 304L stainless steel; journal of materials processing technology 146(2004) 263-272

[8]. Abdul Arif, Abhishek, K.N. Panday; Thermo mechanical modelling for residual stresses of friction stir welding of dissimilar alloys; International journal of engineering science and technology; vol 5 No.06: 11951204. 